\section{Edycasáa

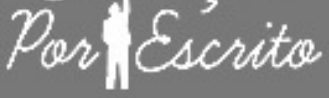

ARTIGO

\section{Editores}

Maria Inês Côrte Vitoria PUCRS, RS, Brasil

Pricila Kohls dos Santos PUCRS, RS, Brasil

\section{Equipe Editorial}

Carla Spagnolo

PUCRS, Brasil

Rosa Maria Rigo

PUCRS, Brasil

\title{
Repercussão da área específica de conhecimento na constituição e expressividade docente
}

\author{
Repercussion of specific areas of knowledge in the constitution \\ and expressiveness of teachers
}

Mirian Haubold Barbosa ${ }^{a}$ Silvia Maria de Aguiar Isaiab Claudia Terezinha Quadrosc

\section{RESUMO}

Este trabalho tem como tema, a influência da área específica do conhecimento na concepção e na atuação docente. A pessoa docente engloba todas as suas facetas mentais, psicológicas e relacionais, traçadas em um perfil próprio, elaborando e reelaborando a si mesma. Esse processo vivencial ancora-se nessa matriz pessoal, através de experiências sensíveis ao meio relacional, integrando as três dimensões: pessoal, espacial-temporal e qualidade de ambiência. Objetivamos compreender a maneira e em que medida o conhecimento específico interfere na construção da trajetória docente no exercício da atividade formativa. Utilizamos a abordagem qualitativa de cunho narrativo envolvendo a análise de entrevistas de docentes das áreas de Ciências Exatas e da Terra e das Ciências Sociais e Aplicadas. Para metodologia escolhemos a análise textual discursiva, a partir de um processo elaborativo de sentido e significado, ressaltam a importância da relação pessoa-professor-área específicas.

Palavras-chave: Conhecimento específico; Formação docente; Expressividade docente

\section{ABSTRACT}

This study explores the influence of specific areas of knowledge in the constitution and performance of teachers. Teachers encompass all their mental, psychological and relational facets in their own profile, elaborating and re-elaborating themselves. This experiential process is anchored in a personal matrix via experiences that are sensitive to the relational environment, integrating three dimensions: personal, spatial-temporal and quality of ambience. The aim is to understand how and to what extent specific knowledge interferes in the construction of the teaching trajectory in the exercise of the formative activity. A qualitative approach of narrative character was used, involving the analysis of interviews of teachers from the areas of exact and earth sciences and social and applied sciences. Discursive textual analysis was used as methodology, based on an elaborative process of sense and meaning, emphasizing the importance of the specific person-teacher-area relationship.

Keywords: Specific knowledge; Teacher training; Teacher expressiveness

a Doutora em Educação. Docente da Universidade Federal de Santa Maria

b Doutora em Educação. Docente do Centro Universitário Franciscano.

c Doutoranda em Educação na UFSM. Professora do curso de Educação Física da ULBRA, Campus Cachoeira do Sul e Santa Maria. 


\section{Introdução}

temática deste trabalho é a influência da área específica do conhecimento na concepção e na atuação docente. O

objetivo é compreender de que maneira e em que medida o conhecimento específico interfere na construção da trajetória docente, na elaboração do saber acadêmico e no exercício da atividade formativa.

Parte-se da ideia básica de que a formação pessoal ampara a formação profissional, à medida que se entende o formador como um ser unitário, constituído de uma história vivencial/experiencial de pessoa e de professor. Constituição e construção histórica da vida que envolvem a si mesmo como produto da integração de representações - estando em constante mudança -, definidas pelas relações reais e imaginadas consigo, com outros significativos e nos diversos espaços e tempos de vivências e experiências (BARBOSA, 2005).

Este artigo aborda resultados parciais do projeto de pesquisa "Os movimentos da docência superior: construções possíveis nas diferentes áreas de conhecimento", que vem sendo desenvolvido pelo Grupo de Pesquisa Trajetórias de Formação (GTFORMA).

A relevância do trabalho reside na aproximação entre as áreas específicas de conhecimento e a área formativa e no registro inovador do processo formativo vivencial docente, sob a ótica da especificidade e da formação. Assim, proporciona aprofundar a reflexão sobre a formação docente, estabelecendo novos entendimentos sobre a construção dessa identidade.

Este estudo teve uma abordagem qualitativa de cunho narrativo (CONNELLY; CLANDININ, 2009; MCEWAN, 1998; BOLIVAR; DOMINGO; FERNÁNDEZ, 2001; GOODSON, 2004), envolvendo a análise de entrevistas narrativas de docentes de uma instituição pública de ensino superior do interior do Estado do Rio Grande do Sul. A pesquisa foi desenvolvida a partir da narrativa de 60 sujeitos. Entretanto, o recorte apresentado aqui enfoca somente uma análise parcial dos sujeitos das áreas de Ciências Exatas e da Terra e das Ciências Sociais e Aplicadas.

No encaminhamento metodológico, escolheu-se o método de análise textual discursiva (MORAES, 2003; MORAES; GALIAZZI, 2007), utilizaram-se as narrativas dos professores para que se pudesse entender a fala destes, na medida em que se compreende a linguagem como um instrumento de comunicação e interpretação de caráter intersubjetivo. As falas dos docentes foram narradas e posteriormente interpretadas, de forma a possibilitar entendimentos sobre esses docentes, uma vez que a narrativa permeia o mundo objetivo, o mundo social e o mundo subjetivo de cada um dos envolvidos.

Utilizou-se como material de estudo entrevistas narrativas colhidas com 16 sujeitos das áreas Exatas e da Terra e Sociais e Aplicadas.

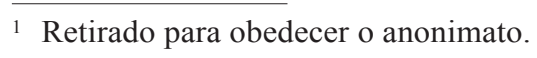


Tendo por base Moraes e Galiazzi (2007) para análise e interpretação dos dados da pesquisa, considerou-se a emergência de quatro momentos, explicitados a seguir.

O primeiro momento foi de entendimento para a apropriação dos objetivos do presente artigo e uma busca de amparo bibliográfico com finalidade de imersão no universo teórico.

No segundo momento, foram revisadas e rediscutidas as narrativas, objetivando elaborar categorias por áreas específicas do conhecimento, entrelaçadas aos anos de docência através de uma análise minuciosa desses textos. Além de anotações das informações consideradas relevantes acerca da temática do trabalho, o que se denomina unitarização dos termos ou desmontagem dos textos. Isto é, o exame dos materiais em seus detalhes, fragmentando-os no sentido de atingir unidades constituintes.

O terceiro momento caracterizou-se pela construção de relações entre as unidades, combinando-as e classificando-as no intuito de permitir a compreensão (MORAES; GALIAZZI, 2007). Esse processo pode ser denominado categorização e demanda construir relações entre as unidades de base, combinando-as e classificando-as no sentido de compreender como esses elementos unitários podem ser reunidos na formação de conjuntos mais complexos. Considera-se que essa análise se constituiu em um trabalho denso ao qual se chegou a determinadas categorias que foram orientadoras para as ideias conclusivas.

O quarto e último momento constituiu-se na produção do metatexto, ou seja, um novo entendimento, resultando no processo elaborativo de sentido e significado das categorias. Conforme Moraes e Galizazzi (2007), o metatexto pode ser considerado como a construção de um novo texto que se origina a partir dos textos originais, expressando a compreensão do pesquisador sobre os significados e sentidos construídos a partir desses achados.

Dessa forma, buscou-se a integração das dimensões do conhecimento específico de cada área aos saberes acadêmicos, entendidos como apropriação ativa nas trajetórias pessoais e profissionais dos professores e como resultado de uma produção social. Podendo estes ser submetidos às revisões e reavaliações, resultantes da interação entre sujeito imerso em um dado contexto. As considerações finais resultam de possíveis modos de pensar, de agir e de constituir-se na ação pedagógica, em um permanente questionar ativo, no qual conhecimentos específicos e saberes acadêmicos estão sendo (re)construídos acerca da cultura e pedagogia universitária peculiar à atuação docente.

\section{Sustentação teórica}

O fio condutor do artigo é o entendimento de que a pessoa docente engloba todas as suas facetas mentais, psicológicas e relacionais, traçadas em um perfil próprio, elaborando e reelaborando a si mesma, seu núcleo identitário. Esse processo vivencial ancora-se nessa matriz pessoal, mas também em experiências sensíveis ao meio relacional, 
integrando as três dimensões que têm sido alvo de atenção: a pessoal, a espacial e temporal e a dimensão da qualidade de ambiência (BARBOSA, 2013).

Quando se pensa em matriz pessoal, remete-se a Abraham (1987), que ilumina a concepção do professor a partir de sua constituição pessoal, ou seja, de seu mundo interno e em relação ao mundo externo profissional. Dessa maneira, explicita a constituição de um sistema multidimensional, que compreende as relações do indivíduo consigo mesmo e com os demais significantes da coletividade com a qual se relaciona. Na base desse sistema estão as imagens, as atitudes, os valores, os sentimentos, os conhecimentos presentes que irão conceber a sua identidade profissional. Assim, é estabelecida uma trama na qual circulam os elementos que o concebem como docente através de um processo identitário, que se desenvolve no tempo e no espaço das vivências. A partir desse pensamento, entende-se que os conhecimentos científicos e os saberes científicos são elementos que compõem tal identidade, pois são valores significativos da coletividade, da matriz pessoal e profissional docente.

De acordo com as ideias de Heller (1982) e Isaia (2003), a construção do conhecimento de ser professor origina-se das funções de sentir, pensar e agir, do desejável pensamento reflexivo, de atitudes de respeito, flexibilidade e autonomia e da curiosidade. Desse modo, estabelecida a constituição do professor, resulta o perfil desejado desse profissional - alguém capaz de atuar de forma sensível, numa rede de ações, reflexões, conhecimentos e novas concepções através da experiência. Percebe-se que, através dessa ótica, entrelaçam-se os constituintes afetivos, cognitivos e comportamentais do docente, sendo sediados e regidos por si mesmo, e direcionados pelos sentimentos que surgem da compreensão e interpretação do vivenciado.

Alinhada a tais pensamentos, Josso (2004, p. 48) clarifica que "a formação é experiencial ou então não é formação, mas a sua incidência nas transformações da nossa subjetividade e das nossas identidades pode ser mais ou menos significativa". Para a autora, o sujeito é o centro dos seus processos constitutivos de identidade, de subjetividade e de conhecimento, amalgamando as dimensões pessoais, profissionais e contextuais, entendendo-o como sujeito e objeto nos caminhos que conduzem a uma construção intencional de um adulto em autoformação.

Fundamentada nos estudos de Josso, Barbosa (2013) aborda que o docente é compreendido em suas dimensões existenciais, pessoais, relacionais e instrumentais. As suas consequentes aprendizagens de si mesmo, de suas práticas, de suas compreensões e explicações acontecem em espaços internos, externos e naturais, considerando os tempos presentes, passados e futuros. E o presente é o momento de rememorar e elaborar o passado para que o futuro seja criativo e gerativo.

Partindo do princípio de que uma experiência é formadora quando simboliza comportamentos, pensamentos, ações e sentimentos que caracterizam uma subjetividade e identidades, Josso (2004) propõe que: 
[...] os conhecimentos são frutos de experiências próprias em uma dialética entre interioridade e exterioridade, entre individual e coletivo, que está sempre presente na elaboração de uma vivência em experiência formadora, porque esta última implica a mediação de uma linguagem e o envolvimento de competências culturalmente herdadas (JOSSO, 2004, p. 49, grifos da autora).

Esse processo de elaborações subjetivas se dá em direção longitudinal - perfazendo uma história vivencial e em direção transversal, e compondo momentos da vida - e acontece inserido em determinada ambiência ${ }^{2}$ (MACIEL, 2000). Além de ser traduzido por consequente expressividade nas relações intrapessoais e interpessoais, em diferentes graus de profundidade e em determinado clima afetivo. Nesse processo, ambiência e expressividade tendem a facilitar ou dificultar o processo da formação (BARBOSA, 2013). Lembra-se aqui de Heller (1982) ao falar sobre o ser, estar e sentir docente e sobre as reflexões de Maciel (2009) a respeito de ambiência interna e externa do professor. Ressaltase que o mundo interno do docente (ABRAHM, 1987) torna-se um espaço-ambiente essencial aos movimentos formativos e encontra forte ressonância com o mundo externo da formação. Essa dupla ambiência será adequada para a experiência autoformativa (JOSSO, 2004), quando houver um clima emocional de confiança, e permitirá a tranquilização das ansiedades e dos sentimentos despertados nos processos evolutivos, que exigem mudanças pessoais. Situação que possibilita fantasiar, imaginar, realizar e expressar essas condições que serão geradoras de novas possibilidades formativas.

Quando se pensa em processos pessoais de elaboração identitária, nos espaços e tempos da formação, em ambiência interna e externa, lembra-se que a dinamização dos conhecimentos específicos são conceitos básicos de determinada área implicados no modo de entender seu processo de construção, estruturação e desenvolvimento de estratégias pedagógicas para o encaminhamento das práticas metodológicas. Conceitos fundamentais para estabelecer e reorganizar o fazer pedagógico do docente, como também para que ele possa construir-se como tal. Pressupõe, então, a exigência de conhecimento específico da área e conhecimento pedagógico, que representam a base epistemológica na qual é conduzido o trabalho do professor (ISAIA; BOLZAN, 2007a, 2009).

A partir do que foi exposto, entende-se que a temática fundamental deste artigo, que é a repercussão do conhecimento específico da área na atuação docente, está sintetizada no pensamento de que a professoralidade é entendida como um processo de constante apropriação de conhecimentos/saberes/fazeres próprios ao exercício de

\footnotetext{
2 Ambiência docente como um conjunto de forças ambientais objetivas (externas), subjetivas (intrapessoais) e intersubjetivas (interpessoais), cujas repercussões no processo de desenvolvimento da profissional podem permitir ou restringir a [re]significação das experiências ao longo da vida e da carreira e, consequentemente, da trajetória formativa.
} 
cada profissão. E, para tal, as ideias de conhecimento pedagógico compartilhado através de trocas intersubjetivas e interdiscursivas são indispensáveis. A professoralidade implica também a sensibilidade do docente como pessoa e profissional em termos de atitudes e valores, tendo a reflexão como componente intrínseco ao processo de ensinar, de aprender, de formar-se e, consequentemente, de desenhar sua própria trajetória (ISAIA; BOLZAN, 2009). Entende-se que a constituição da pessoa-professor promove a elaboração da identidade docente, ou seja, o entendimento de si mesmo como professor, a partir de uma evolução histórica que integra as diversas dimensões que o constituem.

\section{Resultados e discussões}

O processo elaborativo de sentido e significado explicitado anteriormente possibilitou o agrupamento dos resultados deste estudo em categorias. Esse processo analítico levou em consideração três eixos norteadores que serviram como parâmetro para a objetivação da análise.

No Eixo I, referente à área do conhecimento específico, elaboraram-se as categorias Pano de Fundo, Rede Conceitual e Inter-Relação Interna e Externa. A categoria Pano de Fundo, entendida como fundamento essencial a partir do qual o docente se movimenta, representa uma essência pessoal que ampara o seu modo de sentir, pensar e agir na própria atividade docente. Aqui, recordam-se Abraham (1987), ao falar da matriz pessoal que ampara a constituição interna do professor, e Heller (1982), ao destacar a implicação como um sentimento construtivo e integrador da constituição e expressividade do professor. Assim, está presente na constituição afetiva do docente, traduzindo seus motivos íntimos e seu modo de dar sentido à sua existência, direcionada à sua profissão, ao seu "ser professor". Através dessa essência, ele elabora suas concepções de maneira peculiar. Percebe-se que existe, tanto numa área quanto na outra, marcas da trajetória pessoal e do conhecimento específico. Alinhada a tais ideias e evoluindo-as, Josso (2004) aponta a significativa importância dos processos vivenciais e experienciais constitutivos da identidade docente, tendo como fundamento esse elaborar contínuo, que se traduz na construção do saber, fazer e ser docente. Desse modo, é fundamental a integração processual das dimensões afetivas, cognitivas e comportamentais perante o contexto em que se constitui o exercício da docência. Em linha convergente, Isaia (2012), em suas produções, ressalta o docente como um ser unitário que se constitui ao longo de suas trajetórias pessoais e profissionais inserido em um contexto sociocultural.

Dentro dessa linha de pensamento, encontrou-se coerência nos resultados obtidos, pois nas duas áreas estão as mesmas facetas compondo o pano de fundo, porém, com ênfases expressivas diferentes. Nas áreas Sociais e Aplicadas, transparece um matiz de marcas pessoais, indicando uma pessoalidade entendida como resultante de um 
processo de elaboração de vivências e conhecimentos marcados pela especificidade da área em questão. Já nas Exatas e da Terra, a ênfase se faz presente no conhecimento específico, apontando para uma conceitualidade compreendida como uma maneira de elaborar a docência calcada nos conceitos epistêmicos e sinalizando a influência do universo da área específica em questão. Ressalta-se que o pano de fundo é um mosaico que fundamenta a constituição e a expressividade docente e guarda marcas peculiares pessoais e da especificidade profissional, como se apresenta abaixo:

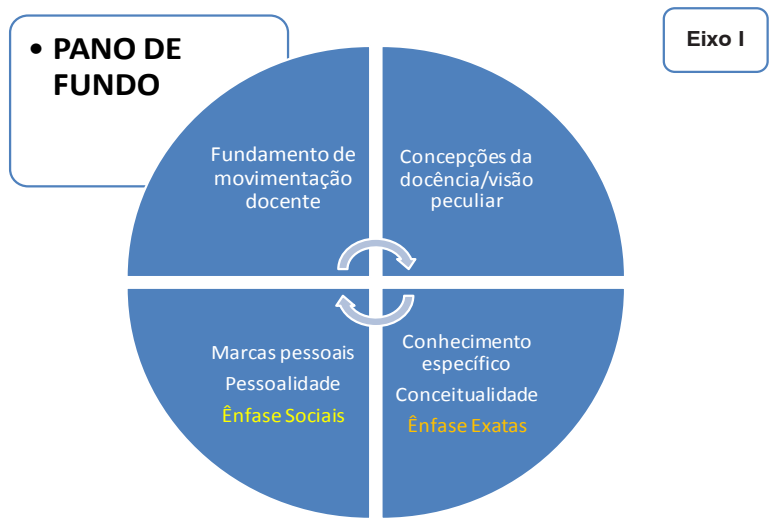

Figura 1. Pano de Fundo

Na categoria Rede Conceitual, a compreensão é de que através do pano de fundo cada professor elege determinados conceitos que lhe são mais significativos. Então, começa a relacioná-los entre si, estabelecendo uma rede de conceitos que ancora seu modo de pensar e exercer suas ações docentes. Salienta-se que essa maneira de associar conceitos guarda um processar construtivo do exercício docente que coloca em relação facetas pessoais e profissionais como resultante de tal processar, e percebem-se nuances diferentes em cada área de conhecimento.

Sublinha-se que nessa categoria de rede conceitual há a presença do pensamento dos autores que fundamentam este trabalho, no sentido de que o estabelecimento de determinada rede de conceitos, a maneira de relacioná-los e expressá-los no ato de ensinar, é a expressão cognitiva da singularidade do docente. Singularidade que se ancora no contínuo elaborar da tríade pessoa-professor-área de conhecimento específico. 
Dessa forma, observa-se que existe, tanto numa área quanto na outra, um processo de subjetivação e objetivação da dinâmica própria de cada docente. Contudo, existe uma ênfase de objetivações na área das Exatas e da Terra e de explicitação de movimentos subjetivos na área das Sociais e Aplicadas. Situação que denota maior expressividade via linguagem descritiva na primeira e via linguagem subjetiva na segunda, o que estimula processos de objetivação e de elaboração com matizes específicos de cada área.

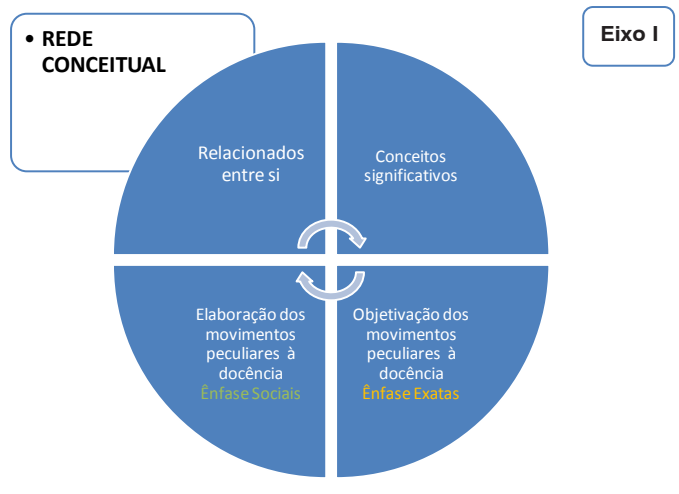

Figura 2. Rede Conceitual

Na categoria Inter-Relação Interna e Externa, enfoca-se a dinâmica relacional que o professor estabelece com o conhecimento, ou seja, o significado deste nos contextos intrapessoal, interpessoal, disciplinar e com áreas afins. Toda essa dinâmica é permeada por uma construção que envolve o sentir, o pensar e o agir desse profissional, uma vez que é um processo de elaboração de sentido e significado para o conhecimento específico e para o exercício formativo. Percebe-se nessa dinâmica elaborativa direcionamentos com base na inserção social e na própria ciência. Clarifica-se que, na inserção social, o docente relaciona o conhecimento com os movimentos sociológicos para dar-lhe sentido e significado; e, na inserção científica, o professor relaciona-os com os movimentos de evolução científica. Assim sendo, a área das Exatas e da Terra enfatiza uma inter-relacionalidade com base na ciência, e as Sociais e Aplicadas, na sociedade. Tal fato é coerente com a especificidade de uma e de outra área. Nesse sentido, também encontra eco nas ideias de Heller (1982). Segundo ele, ao estar implicado, o professor sente algo, um sentimento. Sentir algo é uma expressão de si mesmo que se inicia no espaço intrapessoal e torna-se um elemento de ligação e de regulação na esfera interpessoal. Heller $(1982$, p. 72) reitera dizendo que [...] "sentir no es meramente una experiencia 
subjetiva, sino también una expresión. El sentimiento se expresa em la mímica, en gestos, en elementos fonéticos [...] en comportamiento en general"'3. Entende-se, assim, que conforme a relação estabelecida com o conhecimento na esfera intrapessoal será a expressividade de tal relação na esfera interpessoal, tanto no contexto disciplinar quanto nas áreas afins. Corrobora com essa ideia Isaia (2003b, 2006a), quando fala sobre a concepção de docência que norteia a forma como o professor entende seu fazer docente associado a uma pluralidade de compreensões, em que acontecem complexas ações e reações no universo docente.

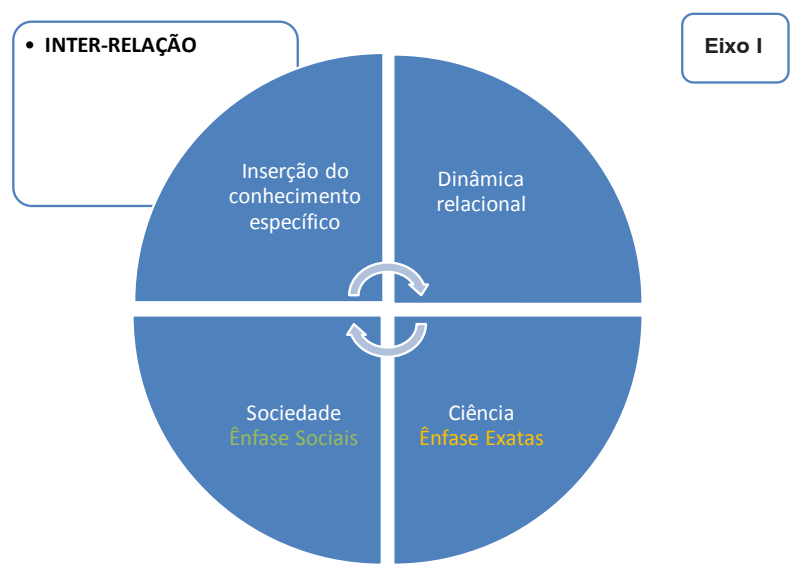

Figura 3. Inter-relação

O Eixo II refere-se à articulação entre o conhecimento específico e o saber acadêmico. Obteve-se como resultado as categorias Maneira Peculiar de Construir o Saber Acadêmico e Elemento de Articulação. A categoria Maneira Peculiar de Construir o Saber Acadêmico está relacionada ao modo pelo qual cada docente constrói a dinâmica de transposição de seu arsenal de conhecimentos específicos para o saber acadêmico, sendo este determinado como significativo para o exercício formativo dos alunos. Em relação a essa dinâmica de transposição, pensa-se

3 “[...] sentir não é meramente uma experiência subjetiva, senão também uma expressão. O sentimento se expressa na mímica, nos gestos, em fonemas, no comportamento em geral” (tradução do(a) autor(a) deste artigo). 
que está ligada à singular maneira de processar as diversas dimensões que envolvem a constituição da própria identidade docente. Nessa construção, está revelada a maneira única com que tal professor estabelece ligações entre conhecimento especifico, rede conceitual, saber acadêmico e marcas pessoais.

A categoria Elemento de Articulação, é resultante de um processar contínuo do ser, sentir, pensar e agir docente. E é na elaboração vivencial dessa complexa dimensionalidade que se configura algum elemento de transposição, no qual o professor se ampara para estabelecer a conexão entre o conhecimento específico e o saber acadêmico.

Observa-se o quanto essa categoria está sustentada nos estudos de Heller (1982) e de Josso (2004), pois aludem a integração das diversas dimensões pessoais e profissionais do docente em um processo vivencial e experiencial da formação.

Foram encontrados os seguintes elementos: condução do grau de conhecimento, partindo do mais simples para o complexo; historicidade da ciência; inserção social; e compreensão subjetiva do aluno.

$\mathrm{O}$ elemento que parte do conhecimento simples para o mais complexo refere-se à atitude do professor ao possibilitar o entendimento do aluno através de conhecimentos básicos em direção aos mais complexos da área, facilitando, assim, a evolução do pensamento do aluno. Já no elemento historicidade da ciência, o formador estabelece a articulação se valendo da evolução histórico-científica da área específica. No elemento inserção social, a transposição é realizada através de uma contextualização a partir de eventos sociais que necessitam e estimulam a produção de conhecimento. O elemento compreensão subjetiva do aluno está vinculado às relações estabelecidas entre o professor e o aluno, de tal modo que a percepção sensível docente ancora a transposição do conhecimento efetuada no processo de ensino-aprendizagem.

De forma coerente com os outros eixos, as categorias estão presentes nas duas áreas, porém com forças diferentes. Na área Exatas e da Terra, o elemento de articulação que se sobressai fala da força científicoconceitual e, nas Sociais e Aplicadas, na força das relações interpessoais como meio de cultivo para a construção docente. Nesse eixo, a partir de dimensões universais da docência, faz-se proeminente a marca da área específica do conhecimento na constituição do docente e sua expressividade.

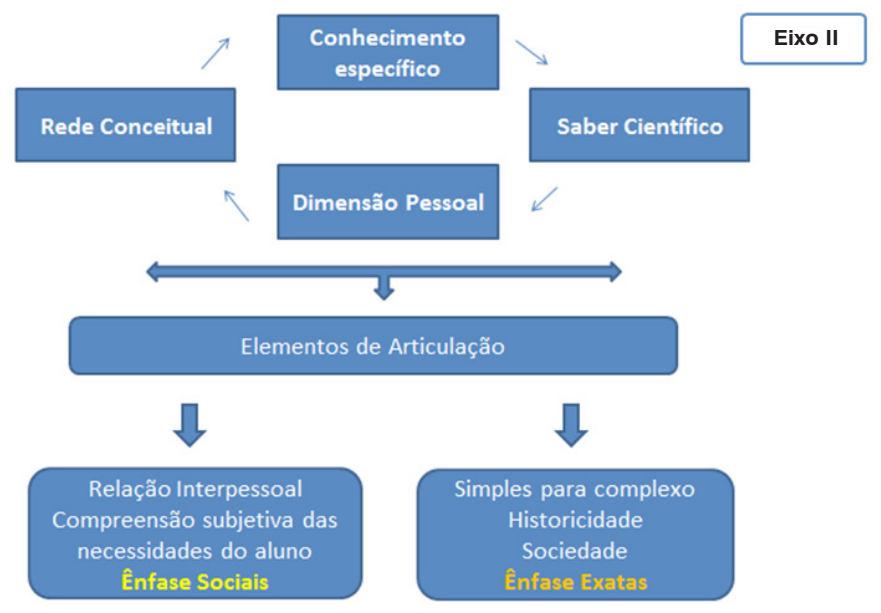

Figura 4. Eixo II 
O Eixo III refere-se à área do conhecimento acadêmico em ação, desvelando como cada professor vivencia e experiência a sua singular docência. Aqui, elaboram-se as categorias Impressão das Marcas Pessoais na Docência; Concepções Próprias da Docência; Percepção do Aluno; e Pontos de Tensão.

A categoria Impressão das Marcas Pessoais na Docência revela as influências das características pessoais no exercício docente, bem como nas relações estabelecidas nesse exercício. Dessa maneira, desvela-se a influência do mundo interno e a história vivencial desse profissional nas relações estabelecidas com as outras dimensões que contribuem para a produção do trabalho formativo. Essa categoria se faz ressonante e consoante com o pensamento de que a constituição pessoal e a profissional são processos complementares em uma contínua elaboração de si mesmo. E esta tem como matriz o espaço de mundo interno em estreita interdependência com o espaço de mundo externo, construindo uma intensa rede de relações interpessoais e intrapessoais no universo da docência (BARBOSA; ISAIA, 2012).

Pode-se perceber que isso encontra amparo nos aportes de Abraham (1987), ao dizer que a matriz da constituição do professor é pessoal, e de Josso (2004), ao considerar o exercício da formação como espaço e tempo (auto) formativo, no qual reúnem-se os aspectos subjetivos, os de conhecimentos e os identitários.

A categoria Concepções Próprias da Docência mostra uma maneira única de cada professor elaborar e agir a sua docência, demonstrando as condições subjetivas desse professor para elaborar a si mesmo, seus conhecimentos e sua identidade profissional, condições singulares que estão entrelaçadas nos diversos contextos e tempos da profissão. E deixa transparecer suas questões subjetivas, seus ideais, seus conhecimentos, saberes e fazeres; enfim, seu modo de dar significado às facetas afetivas, cognitivas e comportamentais que compõem a professoralidade (JOSSO, 2004; ABRAHAM, 1987; HELLER, 1982; ISAIA; BOLZAN, 2009).

A categoria Percepção do Aluno revela as condições de cada professor perceber e compreender as dimensões afetiva, cognitiva, comportamental e valorativa de seus alunos. Dessa forma, remete às capacidades de uma percepção sensível, flexível, respeitosa e responsável disponibilizadas ao aluno para o exercício das funções de um professor. Pode-se perceber que ideias que amparam esse trabalho ressaltam o valor de um professor pautado pela percepçãosensível, pelo pensamento reflexivo e pela atitude respeitosa ao transitar nos caminhos intersubjetivos da docência. Lembra-se Isaia (2006, p. 360), quando afirma que o professor gerativo "é empolgado com a docência e apresenta como peculiaridade o cuidar, que está vinculado a uma necessidade psicológica que o leva a sentir-se responsável tanto pelo desenvolvimento de seus alunos e seus colegas mais jovens quanto por suas produções individuais e grupais".

A categoria Pontos de Tensão mostra os fatores que dificultam o exercício docente sob a ótica dos professores. Um desses pontos é o equilíbrio entre produção científica e atividade formativa; e outro representa a discrepância entre a própria visão crítica em relação ao funcionamento institucional e acadêmico e a realidade desses funcionamentos. 
Consoante com o presente estudo, pode-se dizer que os pontos de tensão se estabelecem a partir das relações interioridade-exterioridade, imaginação-realidade, ambiência interna-externa, singularidade-coletividade, que são interfaces entendidas como significativas na constituição e no trabalho do docente. Nessas interfaces estão presentes as próprias expectativas de si, do outro e do contexto em confronto com a realidade possível, tanto pessoal quanto profissional, institucional e cultural (ABRAHAM, 1987; JOSSO, 2004; MACIEL, 2000; BARBOSA, 2013). Desse modo, é possível perceber que as dificuldades encontradas pelos docentes vêm de dimensões diferentes e podem estar relacionadas com a especificidade da área, com o contexto da profissão, com o contexto do curso ou com o próprio docente e suas concepções sobre formação dos sujeitos.

Quando se analisam essas três categorias, entende-se que a formação de um educador é uma elaboração de seu mundo interno (ABRAHAM, 1987), que carrega marcas da história pessoal e profissional e mantém laços com o contexto vivencial e experiencial, compondo um processar singular ao elaborar a (auto)formação (JOSSO, 2004). Também acredita-se que a professoralidade é construída ao longo da historicidade que conduz a uma maneira peculiar de integrar as dimensões que compõem o universo da vida docente (ISAIA; BOLZAN, 2009). Nessa perspectiva, compreende-se que o professor necessita ser capaz de estabelecer uma diferenciação entre sua subjetividade e outra subjetividade, entre realidade e fantasia, além de diferenciar uma norma, um fato, um afeto, um papel social, uma opinião, sob pena de comprometer a realização adequada de sua produção docente.

Observa-se que novamente estão presentes as três categorias nas duas áreas de conhecimento específico estudadas. Contudo, nas Exatas e da Terra, existe uma centralidade no professor, que se manifesta apoiado mais expressivamente nas próprias características ao conceber sua docência e ao expressar-se para alunos, fundando-se, com maior ênfase, nos pilares cognitivos e científicos. Já nas Sociais e Aplicadas, o foco está na relação interpessoal, que transparece uma maior entonação nos movimentos intersubjetivos ao estabelecer estratégias de estímulo à produção de conhecimento calcado na mutualidade, fundada em conhecimentos experienciais. Os consequentes pontos de tensão advêm das frustrações em relação às expectativas inerentes ao exercício da formação específica e à realidade contextual adversa a este.

Constata-se na análise dessas categorias uma forte repercussão da área específica na concepção e expressão da docência, por se compreender que as Exatas e da Terra estão em maior afinidade com as expressões objetivas do conhecimento e as Sociais e Aplicadas estão em maior sintonia com as questões subjetivas e humanas do conhecimento. Em síntese, as categorias expressas estão presentes na movimentação docente das duas áreas estudadas, mas existe uma diferenciação na maneira com que o professor as enfatiza. Ou seja, nas Sociais e Aplicadas, a relação interpessoal com o aluno, a experiência com este e a crítica reflexiva na docência estão focalizadas. E, nas Exatas e da Terra, a concepção de docência imprime marcas pessoais no exercício docente. 


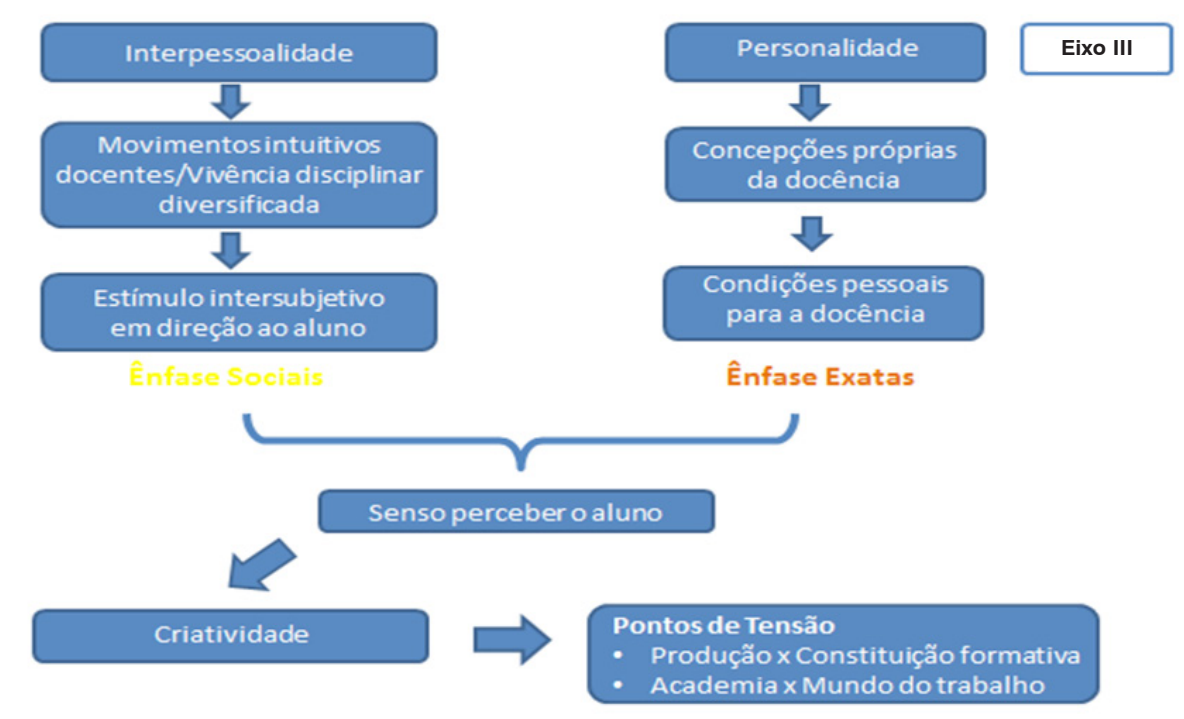

Figura 4. Eixo III

\section{Considerações finais}

Nessa construção de sentido e significado, compreende-se que a área específica de conhecimento exerce influência na concepção e atuação docente de maneira significativa, repercutindo na expressividade docente. As categorias encontradas desvelam dimensões comuns às duas áreas e demonstram que existe ressonância entre a historicidade pessoal e a profissional, que é integrada através de um processo contínuo de elaboração de identidade profissional. Tal processar elaborativo é sediado em uma matriz subjetiva com relação intersubjetiva e inserido na coletividade social, cultural, científica e institucional de cada profissão específica. Assim, a forma como concebem a docência e como atuam nesta é peculiar a cada área, ou seja, a maneira como elaboram tais dimensões as diferenciam. Esse modo de conceber a docência mostra íntima complementaridade entre todas as dimensões e abre novos questionamentos a respeito das repercussões entre estas. 
Acredita-se que a área das Exatas e da Terra dá ênfase às próprias características no exercício da docência. Privilegiam as questões teóricas e cognitivas perante o aluno, influenciando, assim, o modo como o percebem. Nesse contexto, o professor se conduz por uma atitude mais objetiva, direcionando os movimentos de ensino e aprendizagem marcados por um estilo de transmissão de conhecimento.

Já a área das Sociais e Aplicadas enfatiza as relações interpessoais, prestando especial atenção aos movimentos intuitivos na docência e às vivências disciplinares diversificadas. Nessa perspectiva, a sua percepção de aluno o conduz à busca de estímulos intersubjetivos na dinâmica de ensino e aprendizagem, que tem um estilo marcado na reflexão crítica dos aspectos teóricos e profissionais.

Como consequência dessa influência específica inerente a cada uma das áreas, a construção do saber acadêmico acontece através de diferentes elementos que articulam as dimensões envolvidas. Na área das Exatas e da Terra, os professores se amparam predominantemente na construção do conhecimento que se direciona a partir dos conceitos mais simples aos mais complexos; na construção histórica dos conhecimentos específicos, pertencentes à área; e também na inter-relação entre as necessidades da sociedade e a resposta científica para a satisfação destas.

$\mathrm{Na}$ área das Sociais e Aplicadas, a construção do saber acadêmico se apoia em elementos surgidos na relação interpessoal com o aluno e na compreensão subjetiva das necessidades de formação desse aluno, ou seja, é um processo experiencial a partir da vivência cotidiana.

Esses entendimentos remetem a uma visão complexa da dinâmica envolvida nos movimentos da docência superior, reafirmando a existência de um pano de fundo e trazendo a ideia do quão é essencial se entender a pessoa-professor como matriz fundamental para toda movimentação construtiva da docência superior. Essa essência fundamental se torna receptáculo para os conceitos básicos da área de conhecimento específico e, assim, tornase continente e agente, que influenciam significativamente na construção de uma rede conceitual e no processo elaborativo, inter-relacionando todas as dimensões e os elementos envolvidos na concepção e expressividade na docência superior. Tais compreensões levam a ressaltar a importância da relação pessoa-professor-área específica, abrindo caminhos para novos estudos acerca da dinâmica relacional entre tais aspectos do contexto da docência superior.

\section{Referências}

ABRAHAM, A. El mundo interior do los enseñantes. Barcelona: Gedisa, 1987.

BARBOSA, M. A formação do professor - supervisor de terapias psicodinâmicas: um estudo de educação médica. Santa Maria, 2005. Dissertação (Mestrado em Educação) - Programa de Pós-Graduação em Educação, Universidade Federal de Santa Maria. 
BARBOSA, M.; ISAIA, S. Mundo interno e mundo externo: espaços constitutivos do professor-orientador? ANPED SUL, 9., Caxias do Sul, abr. 2012.

BARBOSA, M. Vivências constitutivas do professor-orientador: entre Narciso e Minotauro, um legado e uma despedida. Santa Maria, 2013. Tese (Doutorado em Educação) - Programa de Pós-Graduação em Educação, Universidade Federal de Santa Maria.

BOLÍVAR, A.; DOMINGO, J.; FERNÁNDEZ, M. La investigación biográfica-narrativa em educación. Madrid: La Muralla, 2001.

CONNELLY y CLANDININ. Relatos de experiência e investigación narrativa. In: GAMBOA, S. Práxis Educativa, Ponta Grossa, v. 4, n. 1, p. 9-19, jan.-jun. 2009. Disponível em: <http://www.periodicos.uepg.br>. Acesso em: 03 abril 2017

GOODSON, I. Profesorado e historias de vida: un campo de investigación emergente. In: GOODSON, I. (Ed.). Historias de vida del profesorado. Barcelona: Octaedro, 2004. p. 45-62.

HELLER, A. Teoría de los sentimientos. 2. ed. Barcelona: Fontanara, 1982.

ISAIA, S.; ROCHA. A. Projeto "Os movimentos da docência superior: construções possíveis nas diferentes áreas de conhecimento”. Relatório Final. CNPq, 2013.

ISAIA, S. Os movimentos da docência superior: especificidades nas diferentes áreas de conhecimento e sua influência na atuação docente. Projeto de Pesquisa. CNPq/PQ, 2012.

ISAIA, S.; BOLZAN, D. P. V. Construção da profissão docente/professoralidade em debate: desafios para a educação superior. In: CUNHA, M. I. (Org.). Reflexões e práticas em pedagogia universitária. Campinas: Papirus, 2007a. p. $161-177$.

ISAIA, S. Professor de licenciatura: concepções de docência. In: MOROSINI, M. (Org.). Enciclopédia de Pedagogia Universitária. Porto Alegre: Fapergs/Ries, 2003b. p. 263-277.

ISAIA, S. Trajetórias da docência: articulando estudos sobre os processos formativos e a aprendizagem de ser professor. In: ISAIA, S.; BOLZAN, D.; MACIEL. Pedagogia universitária. Tecendo redes sobre a educação superior. Santa Maria: Ed. da UFSM, 2009. p. 121-144.

ISAIA, S. Desafios à docência superior: pressupostos a considerar. In: RISTOFF, Dilvo; SEVEGNANI, Palmira (Orgs.). Docência na Educação Superior. Brasília: Inep, 2006a. v. 5, p. 63-84. (Coleção Educação Superior em Debate).

ISAIA, S. Ciclos de vida profissional docente: delineamento teórico-metodológico específico para professores do ensino superior. In: ALONSO, Cleuza M. M. C. (Org.). Reflexões sobre políticas educativas. ENCONTRO INTERNACIONAL DE PESQUISADORES DE POLÍTICAS EDUCATIVAS. I., 2005, Santa Maria - Universidade Federal de Santa Maria e Universid de la Republica Montevideo, AUGM, 2005. p. 35-44.

ISAIA, S. Professor de licenciatura: concepções de docência. In: MOROSINI, M. (Org.). Enciclopédia de Pedagogia Universitária. Porto Alegre: Fapergs/Ries, 2003b. p. 263-277.

ISAIA, S. Verbetes. In: CUNHA, Maria Isabel; ISAIA, Silvia de Aguiar. Professor da educação superior. In: MOROSINI, Marília (Ed.). Enciclopédia de Pedagogia Universitária: Glossário. Brasília, 2006b. v. 2: p. 367, 368, 369, 371, 373, $376,377$. 
ISAIA, S. Ciclos de vida profissional de professores do ensino superior: um estudo comparativo sobre trajetórias docentes. Relatório Final. Bolsa PQ/CNPq, 2007-2010.

ISAIA, S. Aprendizagem docente: sua compreensão a partir das narrativas de professores. In: TRAVESSINI, C.; EGGERT, E.; PERES, E.; BONIN, I. Trajetórias e processos de ensinar e aprender: práticas e didáticas. Porto Alegre: EDIPUCRS, 2008.

JOSSO, M. C. Experiências de vida e formação. São Paulo: Cortez, 2004.

MACIEL, A. Formação na docência universitária? Realidade e possibilidades a partir do contexto da Universidade de Cruz Alta. Tese (Doutorado) - Universidade Federal de Santa Maria, 2000.

MCEWAN, H. Las narrativas en el estudio de la docência. In: MCEWAN y EGAN (Comps.). La narrativa en la enseñanza, el aprendizaje y la investigación. Buenos Aires: Amorrortu, 1998.

MORAES, R.; GALIAZZI, M. Análise textual discursiva. Ijuí: Ed. Unijuí, 2007.

MORAIS, R. Educação contemporânea: olhares e cenários. São Paulo: Alínea, 2003.

Recebido em: maio/2017

Aceito em: abril/2018

\section{Endereço para correspondência:}

Mirian Haubold Barbosa <miriannhb@yahoo.com.br>

Rua Floriano Peixoto, 1112, sala 33 - Centro

97015-372, Santa Maria, RS, Brasil 